\title{
Thermodynamic optimization of steady-flow industrial chemical processes
}

\author{
Leslie Glasser ${ }^{1}\left[\right.$ ] James Alistair Fox ${ }^{2}\left[\right.$ ] $\cdot$ Diane Hildebrandt $^{2} \cdot$ David Glasser $^{2}$
}

Received: 15 May 2018 / Accepted: 7 December 2018 / Published online: 14 December 2018

(c) The Author(s) 2018

\begin{abstract}
Industrial steady-flow chemical processes are generally organised as a sequence of individually optimised operations. However, this may not achieve overall optimization since material (as recycle), heat and work transfers overall may not be well balanced. We introduce the idea of a preliminary overall thermodynamic balance to produce a reversible process, with the objective of minimising, for both economic and environmental reasons, the quality and quantity of energy used. This balance may later require adjustment to account for the realities of available materials and equipment. For this purpose, we introduce (i) a Carnot temperature, $T_{\text {Carnot, }}$, by which a Carnot machine (an engine which can operate as either a heat pump or a turbine) can supply the required heat at the correct temperature for a process to operate reversibly, that is with least energy, and (ii) the GH Diagram on which Carnot temperature-based processes are plotted in $\Delta G-\Delta H$ space. We demonstrate the utility of this analysis by simple application to the Haber-Bosch process for ammonia synthesis and by a sequence of operations for the synthesis of methanol. We also briefly introduce the state function exergy, which uses the natural environment as the reference base for energy in place of pure elements under standard conditions.
\end{abstract}

Keywords Reversible $\cdot$ Carnot temperature $\cdot$ Energy $\cdot$ Exergy

\section{Introduction}

There is increasing need to minimise the use of energy, particularly high-quality (that is, high temperature) energy, in industrial production, arising from both economic and environmental concerns. Since much of the energy used in industry is provided by the combustion of fossil fuels, a reduction in energy use will also reduce production of the "greenhouse

Leslie Glasser

1.glasser@curtin.edu.au

James Alistair Fox

fox.jima@gmail.com

Diane Hildebrandt

hilded@unisa.ac.za

David Glasser

david.glasser007@gmail.com

1 Department of Chemistry, Curtin Computational Group, Curtin University, GPO Box U1987, Perth, WA 6845, Australia

2 Materials and Process Synthesis (MaPS), College of Civil and Chemical Engineering, University of South Africa, Florida Science Campus, Pretoria, South Africa gas' carbon dioxide with its contribution to global warming. In thermodynamic terms, optimum processes-those requiring least energy — are performed under reversible conditions $[1,2]$. In this paper, we consider the generalised thermodynamics of industrial production and show how production may be optimised towards reversibility by judicious application of material transfers, heat transfers and performances of work. This method contrasts with standard engineering practice where the individual pieces of equipment are optimised and then combined to create the complete process, which may then not be optimal.

The central argument in this paper is that for a process, however complicated, $G$ of a stream represents its potential to do work. Thus, $G$ of the feed material at a selected state (here chosen for convenience to be ambient conditions) represents the maximum work potential of the feed to do work relative to the selected state. An analogy is water flowing down a hill, which has potential energy; if one does not convert this potential to work, say in a turbine as the water flows down to the standard state (sea level in this case), this work is lost forever. It is, in fact, no accident that $\mu$ (Gibbs energy per mole) of a substance is referred to as its chemical potential and thus $\Sigma \mu_{i} N_{i}$ represents the chemical potential of the feed. 
Bejan $[3,4]$ has developed the Entropy Generation Minimisation (EGM) technique while others, such as Chen and colleagues [5], in a series of papers, have taken the EGM approach further. EGM is thermodynamically equivalent to the GH method (GHM) which we present in this paper.

The essence of the entropy minimization procedure EGM is that it deals with the 'universe' of the process, that is, the isolated system together with its thermodynamically involved surroundings. In order to avoid this intricate relationship, classical chemical thermodynamics introduces a new state function, $G(=\mathrm{H}-T S)$, which relates to the properties of the system only while incorporating the effects of the surroundings, and thus reduces the complexity of thermodynamic considerations. There are thus certain advantages to the GHM over the EGM, since GHM removes the need to consider the surroundings explicitly as its effects are incorporated into the thermodynamic equations. $G$ and $H$ are associated with Work and Heat, respectively, concepts that are more intuitive than Entropy, $S$.

Importantly, the GHM considers the process as a whole, not the individual parts, and thus can predict recycles of work, heat and materials required to render the process as reversible as possible. Furthermore, this analysis can be constructed on a two-dimensional graph no matter how complex the process, that is, a flowsheet can be developed for a complete process [14], as seen for example below for the methanol synthesis process. Thus, we have a method for generating flowsheet designs from scratch rather than the traditional method of evolution from older flowsheets.

In this paper we use the term Carnot machine, which is defined [6] as an engine based on a reversible Carnot cycle in which we either recover the work potential from hightemperature heat, rejecting it at ambient conditions, or take heat at ambient conditions and add work to produce hightemperature heat.

Thus, $\Delta G$ between products and feed represents the work potential that can potentially be recovered in the process. If this value is less than zero, and we do not design the process to recover this potential work as in the example of water flowing downhill with no work recovery, we have lost this work potential forever. By contrast, this paper is about designing processes that can recover this work potential before it is lost. We specifically refer to steady-flow processes where the overall Process Box (invoked below) is, in fact, a condensed flowsheet made up from possibly many individual processes performed in separate units/pieces of equipment, in which we attempt to make the $G$ of the products, including any work we extract from or contribute to the process, as close as possible to the feed $G$. In the case where the two are equal, the process is reversible and that is the thermodynamically best that can be done.

In an earlier paper, Glasser [7] introduced the van't Hoff Reaction Box as a descriptive model of an overall chemical process, whereby reactants are introduced into the box, each under their individual prescribed conditions, and products are removed, also each under their individual prescribed conditions, resulting in thermodynamic changes overall, while no enquiry is made as to the processes occurring or equipment used within the confines of the box. This equipment may consist of pumps to generate pressure and produce isentropic flow, heat baths to control temperature, material recycling to increase output, distillation columns or condensers to separate materials, and so forth.

Where reactants enter and products leave as pure components, each under standard conditions of ambient temperature and pressure, the net changes are described by thermodynamic state functions:

$\Delta_{\mathrm{r}} X^{0}=\sum\left(X_{\text {products }}^{0}-X_{\text {reactants }}^{0}\right)$ where $X^{0}=G^{0}, H^{0}, S^{0}$.

Figure 1 extends the simple van't Hoff Reaction Box model by introducing a Carnot machine, thus incorporating the effects of heat transfer and work performance. We introduce the term "Process Box" to refer to this enhanced system.

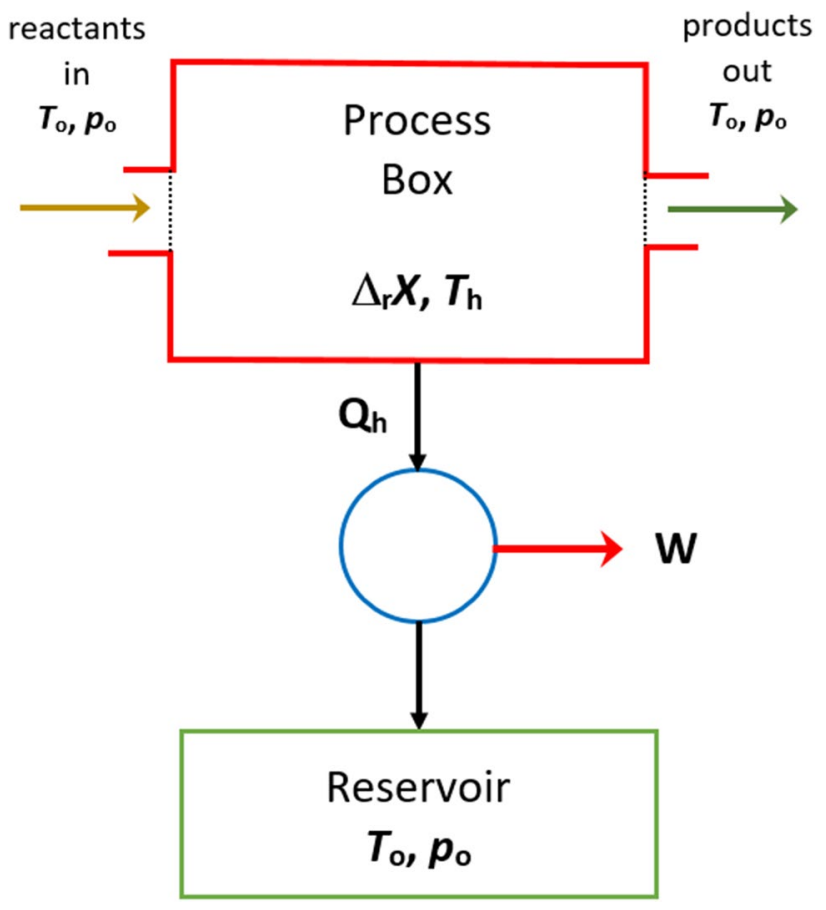

Fig. 1 A Process Box for an exothermic process where heat, $Q_{\mathrm{h}}$, is rejected at a single (high) temperature, $T_{\mathrm{h}}$, and with changes in thermodynamic properties, $\Delta_{\mathrm{r}} X$, resulting from the process occurring within the box. The work, $W$, associated with the heat rejected by the process can be quantified by converting this heat to work in a 'virtual' Carnot machine as depicted. $T_{0}$ and $p_{0}$ are ambient temperature and pressure 
In order for a process to be considered thermodynamically reversible, work done, $W$, in a process needs to be equivalent to the Gibbs energy change, $\Delta G$, as is most readily seen in a reversible electrochemical cell. In most processes, $W$ does not equal $\Delta G$. These processes can and do function, they just do not function reversibly. The goal of the ideas discussed in this manuscript is to make processes more reversible. We do that by examining the Gibbs Energy discrepancy between outputs and inputs. $G$ represents the ability to do work. Should $G$ of the products be less than those of the feed then useful work will be lost forever unless we take it out of the process. Conversely, if $G$ of the products is greater than those of the feed, we need to provide this deficit work to the process otherwise it cannot function. Clearly, any work transfers should be performed as efficiently as possible.

The fundamental equation of thermodynamics [8]

$d G=-S \mathrm{~d} T+V \mathrm{~d} p+\sum_{i} \mu_{i} \mathrm{~d} N_{i}$,

shows that $G$ can be changed by heat transfer over a temperature difference, or by altering the applied pressure, $p$, or by changing the chemical potential sum by mixing or separating chemical components.

In the following preliminary analysis stage, we address only the first term in the fundamental equation of thermodynamics, $-S \mathrm{~d} T$, by considering how temperature differences alone may be used to influence the thermodynamics of a chemical process. Here we consider that heat may carry the potential to do work by virtue of its temperature. High-temperature heat is more useful than lowtemperature heat in terms of the quantity of work that can be extracted from the same quantity of heat. In a subsequent section, we consider how an otherwise impractical process can be made to operate by dividing it into practical steps. This may also be accomplished by using other sources of work such as pressure-volume or electrical energy but, in this paper, we will focus on heat.

\section{Inducing reversibility in a chemical process with heat}

The optimum chemical process, requiring the least work, is a reversible one; we wish to consider how the transfer of heat to or from a process may induce reversibility by supplying or generating the required work.

According to the Carnot principle [9], a quantity of heat $Q_{\mathrm{h}}$ at a (high) temperature, $T_{\mathrm{h}}$, has the potential to generate work, $W_{\text {heat }}$, (by definition, the maximum potential work is the Gibbs energy change, $\Delta G$ ) when the heat is transferred to a reservoir at lower temperature, $T_{0}$ (see Fig. 1). The maximum potential work is quantified by

$W_{\text {heat }}=\Delta_{\text {heat }} G=Q_{\mathrm{h}}\left(1-T_{0} / T_{\mathrm{h}}\right)$.
If heat transfer is the only thermodynamic factor involved, then

$\Delta_{\text {heat }} G=\Delta H\left(1-T_{0} / T_{\mathrm{h}}\right)=T_{0}\left(\Delta S-\Delta H / T_{\mathrm{h}}\right)$.

In order that the overall process for an exothermic reaction in the Process Box be reversible, by using heat alone, $W_{\text {heat, }}$ from the heat transfer must exactly match the maximum potential work produced by the reaction $\Delta_{\mathrm{r}} G^{0}$ :

$W_{\text {heat }}=\Delta_{\text {heat }} G=\Delta_{\mathrm{r}} G^{0}$.

In other words: in order for an exothermic process to be reversible, all of the potential work in the process $\left(\Delta_{\mathrm{r}} G^{0}\right)$ must be recovered as real work $\left(W_{\text {heat }}\right)$. In this case, the exothermic process is the hot reservoir of the virtual Carnot machine, while the environment is the cold reservoir.

As can be seen from Eq. (3), taken together with Eq. (5), for a process to be reversible, resulting in full recovery of the potential work, $W_{\text {heat }}$, while using a specific quantity of heat alone, $Q_{\mathrm{h}}$ (the $-S \mathrm{~d} T$ term), can only be accomplished if $T_{\mathrm{h}}$ is set at a specific temperature relative to $T_{0}$, which we term $T_{\text {Carnot }}[10,11]$, defined in Eq. (7) below. (Note that this definition differs from an earlier independent definition [12], $\Theta=1-T / T_{0}$.)

If $T_{\mathrm{h}}$ is smaller than $T_{\text {Carnot }}$, the work being carried with the heat will be less than the maximum potential work that the process could have produced, resulting in lost work and irreversibility, that is $W_{\text {heat }}$ is negative as is the overall $G$ for the process. However, if $T_{\mathrm{h}}$ is larger than $T_{\text {Carnot }}$ the work (that is, $\Delta_{\mathrm{r}} G^{0}$ ) required for the process to be feasible is greater than the process is capable of producing. Hence, the overall process will not be able to function since the overall $G$ for the process would be positive.

For the case of an endothermic process, the directions of the arrows in Fig. 1 are reversed. The Carnot machine operates in the reverse direction, using an input of work to move heat against the temperature gradient. If the process temperature is below $T_{\text {Carnot, }}$, the heat will not carry enough work into the process and the process will be unable to operate. If the process temperature is above $T_{\text {Carnot }}$, the heat will carry more work into the process than is actually needed. The process will operate but this excess work will be lost, often in undesirable side reactions.

In summary, to produce a reversible process in a Process Box, by provision of heat alone, work must be transferred at the temperature $T_{\text {Carnot }}$, while $Q=\Delta_{\mathrm{r}} H$, so that

$W_{\text {heat }}=\Delta_{r} G^{0}=\Delta_{\mathrm{r}} H^{0}\left(1-T_{0} / T_{\text {Carnot }}\right)$.

\section{The requirements to achieve reversibility: GH diagrams and $T_{\text {Carnot }}$}

From the above relation, it follows that 


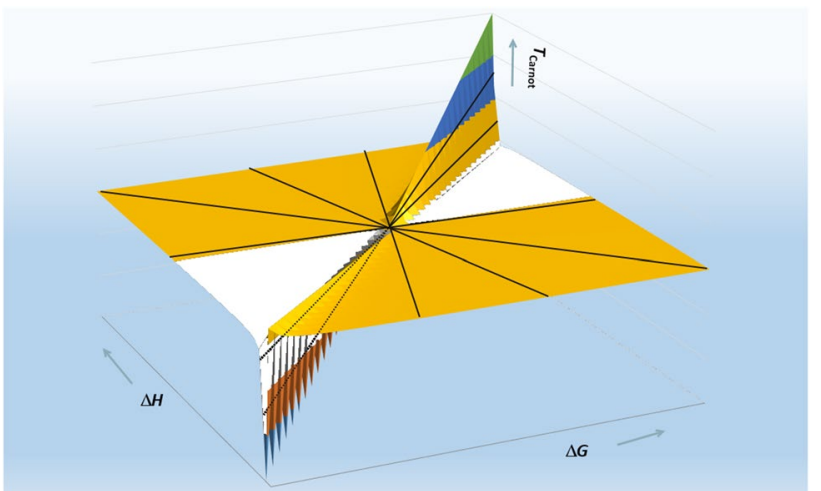

Fig. 2 A three-dimensional representation of $T_{\text {Carnot }}=T_{0} /(1-\Delta G / \Delta H)$ as a function of $\Delta G$ and $\Delta H$. The radial black lines, with constant ratios $\Delta G / \Delta H$, represent constant values of $T_{\text {Carnot, }}$, with the sections lying below the exposed surface shown dotted. $T_{\text {Carnot }}$ tends to infinity as $\Delta G / \Delta H \rightarrow+1$, while attaining impossible negative absolute temperatures in the white regions, when $\Delta G$ / $\Delta H>1$. Note: $T_{\text {Carnot }}$ reaches towards both negative and positive infinity as $\Delta G / \Delta H \rightarrow+1$ but, for convenience and clarity in the Figure, only the negative extreme is shown for the negative $\Delta G, \Delta H$ pair, and only the positive extreme is shown for the positive $\Delta G, \Delta H$ pair

$T_{\text {Carnot }}=T_{0} /\left(1-\Delta_{\mathrm{r}} G^{0} / \Delta_{\mathrm{r}} H^{0}\right)$.

This function may be plotted (Fig. 2) as a three-dimensional diagram.

Fig. 3 GH diagram $[13,14]$ of $\Delta G$ versus $\Delta H$, highlighting the Carnot temperature ( $\left.T_{\text {Carnot }}\right)$ regions. Constant Carnot temperatures lie along radial lines, with the specific Carnot temperatures for an ambient temperature $T_{0}=298.15 \mathrm{~K}$ listed outside the diagram edges. Regions $1 \mathrm{~A}$ and $3 \mathrm{~A}$ are within common operational temperature ranges; regions $1 \mathrm{~B}$ and $3 \mathrm{~B}$ require negative absolute temperatures, $T_{\text {Carnot }}$, and are thus inaccessible to optimization by heat alone, while regions 2 and 4 require refrigeration for optimization. The line RGWS represents the reverse water-gas reaction, Eq. (8), while line DWS represents Eq. (9). The diagram is adapted from Sempuga et al. [14]. Copyright 2010 American Chemical Society

\section{GH diagram}

In order to more easily analyse processes, we use Fig. 3, which is a projection of Fig. 2, based upon an environmental temperature, $T_{0}$, of $298.15 \mathrm{~K}$. Our discussion is based upon that of Sempuga et al. [13]. It is worth noting that the diagonal lines in the diagram represent $|\Delta G|=|\Delta H|$. Since $\Delta G=\Delta H-T \Delta S$, points off the diagonal lines represent conditions of positive or negative entropy contribution, as the case may be. In the following discussion, we assume that $\Delta H$ and $\Delta S$ are independent of temperature and pressure.

\section{Region 1: endothermic processes which require both heat and work}

Region 1 represents processes within the Process Box which require both heat (are endothermic, having positive $\Delta_{\mathrm{r}} H^{0}$ ) and work (with positive $\Delta_{\mathrm{r}} G^{0}$ ) to be supplied in order to be rendered reversible. A Carnot machine working at $T_{\text {Carnot }}$ may provide this resource, where $T_{\text {Carnot }}$ may vary in Region 1A (and 3A) from ambient temperature, $T_{0}$, to infinity. We exemplify this with the reverse water-gas shift reaction (RWGS):

$\mathrm{CO}_{2}+\mathrm{H}_{2} \rightarrow \mathrm{CO}+\mathrm{H}_{2} \mathrm{O}$

where, at $T_{0}$ and $p_{0}$

$\Delta_{\mathrm{r}} G^{0}=28.52 \mathrm{~kJ} \mathrm{~mol}^{-1} ; \Delta_{\mathrm{r}} H^{0}=28.52 \mathrm{~kJ} \mathrm{~mol}^{-1} ;$

$\Delta_{\mathrm{r}} G^{0} / \Delta_{\mathrm{r}} H^{0}=0.69$.

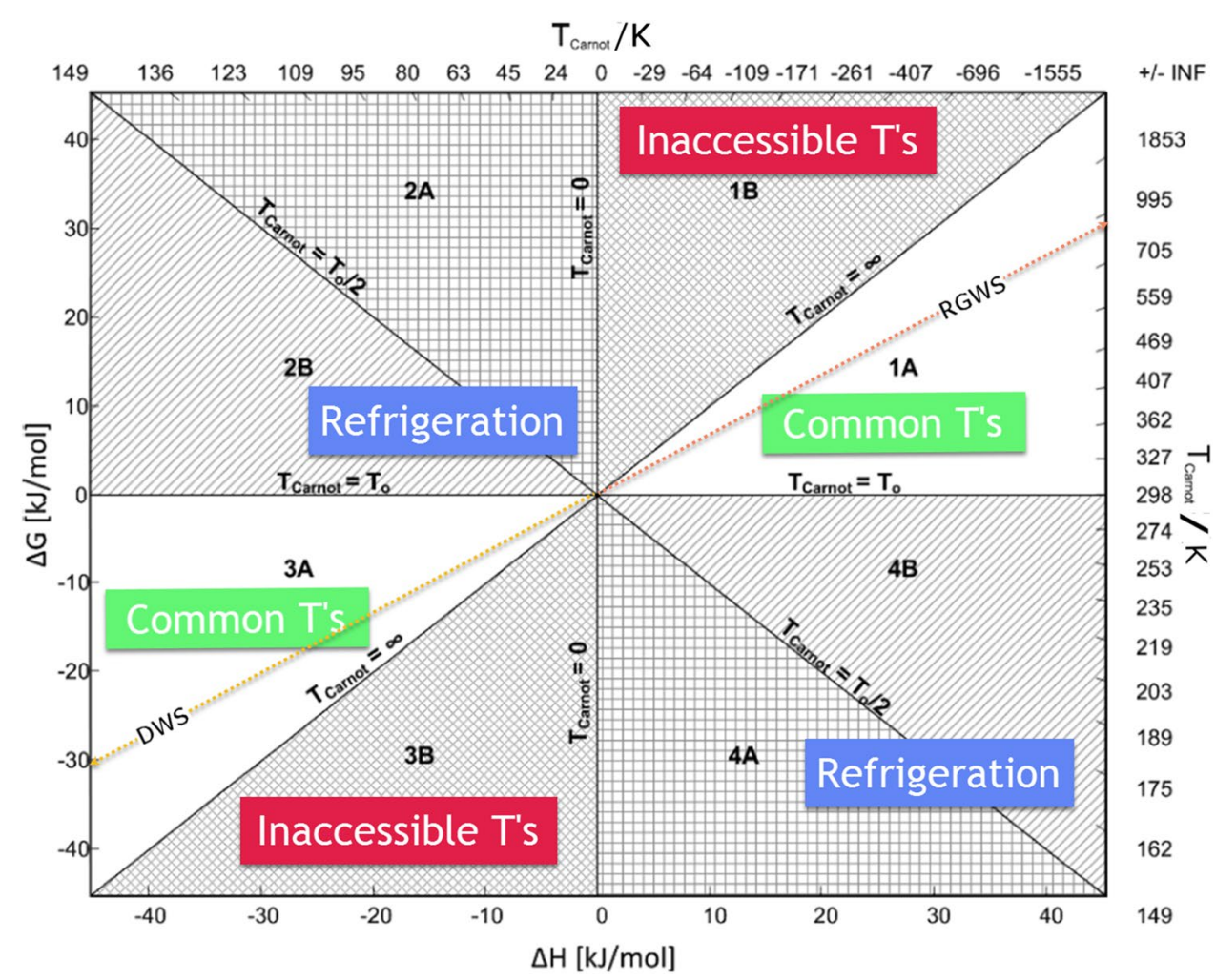


With these values for $\Delta_{\mathrm{r}} H^{0}$ and $\Delta_{\mathrm{r}} G^{0}$, and a reservoir temperature $T_{0}=298.15 \mathrm{~K}, T_{\text {Carnot }}=971 \mathrm{~K}$ (cf. Eqs. 1 or 2).

A process in Regions 1B and 3B, where $\Delta_{\mathrm{r}} G / \Delta_{\mathrm{r}} H>1$, requires $T_{\text {Carnot }}$ to have an impossible negative absolute temperature value. Thus, a Carnot heat engine alone cannot satisfy the requirements to generate a reversible process within these Regions; however, alternative means of providing the required work input are available, such as pressure-volume work or electrochemical work.

\section{Region 2: exothermic processes which reject heat and require work}

Since the processes in Region 2 supply heat, this must be removed in a refrigeration process. The work involved is that which is required to remove that heat. Region $2 \mathrm{~B}$ has $T_{\text {Carnot }}$ between $T_{0} / 2$ and $T_{0}$, which is the more economical refrigeration regime, while Region $2 \mathrm{~A}$ has $T_{\text {Carnot }}$ between $0 \mathrm{~K}$ and $T_{0} / 2$ and is thus likely to be infeasible for practical use.

\section{Region 3: exothermic processes which reject both heat and work}

While Region 3B is unavailable to generate reversible processes because negative temperatures are forbidden, Region $3 \mathrm{~A}$ is advantageous because the heat produced in the reversible process may be used to generate useful work. An example of this process is the dehydration of methanol to form dimethyl ether (DME):

$2 \mathrm{CH}_{3} \mathrm{OH} \rightarrow \mathrm{CH}_{3} \mathrm{OCH}_{3}+\mathrm{H}_{2} \mathrm{O}$,

where

$\Delta_{\mathrm{r}} G^{o}=-16.75 \mathrm{~kJ} \mathrm{~mol}^{-1} ; \Delta_{\mathrm{r}} H^{o}=-24.05 \mathrm{~kJ} \mathrm{~mol}^{-1}$;

$\Delta_{\mathrm{r}} G^{o} / \Delta_{\mathrm{r}} H^{o}=0.70$.

This process may be made reversible with $T_{\text {Carnot }}=983 \mathrm{~K}$.

\section{Region 4: endothermic processes which require heat and reject work}

Processes in Region 4 operate at sub-ambient temperatures. The heat required for the process is drawn from the environment, while the work from the process assists in promoting the heat transfer from sub-ambient to ambient temperature when using an appropriate $T_{\text {Carnot }}$ to render the overall process reversible.

\section{Irreversible processes}

If a process is performed reversibly, there is no entropy generation. On the other hand, if heat is added or removed at a temperature $T$ other than $T_{\text {Carnot }}$, then the process is irreversible, entropy is generated, and Eq. 6 becomes

$W_{\text {heat }} \equiv \Delta_{\mathrm{r}} G\left(T_{0}, p_{0}\right)+T_{0} S_{\text {generated }}=\Delta_{\mathrm{r}} H\left(T_{0}, p_{0}\right)\left(1-T_{0} / T\right)$.

By difference between Eq. 11 and 6, we obtain the entropy generation

$W_{\text {lost }}=T_{0} S_{\text {generated }}=\Delta_{\mathrm{r}} H\left(T_{0}, p_{0}\right)\left(1 / T_{\text {Carnot }}-1 / T\right)$.

If the work lost, $W_{\text {lost }}$, is positive then the process is producing work which cannot be recovered; conversely, if $W_{\text {lost }}$ is negative, then work must be supplied in order for the process to progress. Positive $W_{\text {lost }}$ implies that the Gibbs energy of the process is increased so that, in the GH diagram, the operating temperature lies above the reversible $T_{\text {Carnot }}$ temperature, while negative $W_{\text {lost }}$ implies a reduction in Gibbs energy with an operating temperature below the reversible temperature.

\section{The ammonia process as an example}

We will examine the Haber-Bosch process for the production of ammonia [7] as an appropriate example of the application of the principles considered in this analysis:

$1 / 2 \mathrm{~N}_{2}(\mathrm{~g})+3 / 2 \mathrm{H}_{2}(\mathrm{~g}) \rightarrow \mathrm{NH}_{3}(\mathrm{~g})$

$\Delta_{\mathrm{r}} G^{0}=-16.40 \mathrm{~kJ} \mathrm{~mol}^{-1} ; \Delta_{\mathrm{r}} H^{0}=-45.90 \mathrm{~kJ} \mathrm{~mol}^{-1}$;

$\Delta_{r} G^{0} / \Delta_{\mathrm{r}} H^{0}=0.36$.

Using this thermodynamic data, which lies in region 3A of the $\mathrm{GH}$ diagram, $T_{\text {Carnot }}=464 \mathrm{~K}\left(190.8^{\circ} \mathrm{C}\right)$. The reaction is exothermic and produces work. However, reaction at this temperature would be too slow, and production in industry is performed over an iron catalyst at temperatures from 350 to $500{ }^{\circ} \mathrm{C}$.

A consequence of carrying out an exothermic reaction at a temperature higher than its Carnot temperature is that the Carnot machine is attempting to extract more work from the reaction than the reaction is actually capable of providing. At a temperature of $500{ }^{\circ} \mathrm{C},(773 \mathrm{~K})$ this work deficit [13] is $11.80 \mathrm{~kJ} \mathrm{~mol}^{-1}$.

For this reaction system to function, this deficit in work needs to be compensated in some manner. Since the reaction involves a reduction in the number of gas molecules, from two to one, an increase in pressure forces reaction to product by Le Chatelier's Principle. The required extra work is supplied by applying pressure of about $200 \mathrm{~atm}$ to the system. It is important to note that the increase in pressure is required because of the change in process temperature (see Fig. 4). 
Returning to the fundamental equation of thermodynamics, compensating for a work deficit using pressure is how the second term, $V \mathrm{~d} p$, is used to maintain the reversibility of the process.

It is common practice in catalyst manufacture to design the catalyst for maximum activity, which generally means higher temperature.

The reversible isothermal work for an ideal gas is

$W_{\text {shaft }}=n R T_{0} \ln \left(p_{\mathrm{f}} / p_{\mathrm{i}}\right)$,

With $n=1, T_{0}=298 \mathrm{~K}$, and $p_{\mathrm{i}}=1 \mathrm{~atm}, p_{\mathrm{f}}=200 \mathrm{~atm}$

$W=-8.314 \times 298 \times \ln (200 / 1) / 1000=-13.1 \mathrm{~kJ} \mathrm{~mol}^{-1}$.

This matches the required work of $-11.80 \mathrm{~kJ} \mathrm{~mol}^{-1}$ very closely.

\section{A reversible complex process}

There are often processes which cannot be run by some simple step plus Carnot machine as illustrated above, such as those operating in Regions $1 \mathrm{~B}$ or $3 \mathrm{~B}$ which would require unattainable negative Carnot temperatures. However, by dividing the simple process into two (or more) processes, the first of which can reversibly accept heat at a high Carnot temperature, $T_{\mathrm{h}}$, and the second return the heat reversibly at a low Carnot temperature, $T_{1}$, the process overall becomes reversible. We illustrate such a complex process with the following example [13].

The process of producing methanol from methane, carbon dioxide and water has the following thermodynamics:

$3 / 4 \mathrm{CH}_{4}(\mathrm{~g})+1 / 4 \mathrm{CO}_{2}(\mathrm{~g})+1 / 2 \mathrm{H}_{2} \mathrm{O}(\mathrm{l}) \rightarrow \mathrm{CH}_{3} \mathrm{OH}(\mathrm{l})$

$\Delta_{\mathrm{r}} G^{0}=88.73 \mathrm{~kJ} \mathrm{~mol}^{-1} ; \Delta_{\mathrm{r}} H^{0}=58.52 \mathrm{~kJ} \mathrm{~mol}^{-1}$; $\Delta_{\mathrm{r}} G^{0} / \Delta_{\mathrm{r}} H^{0}=1.52$.

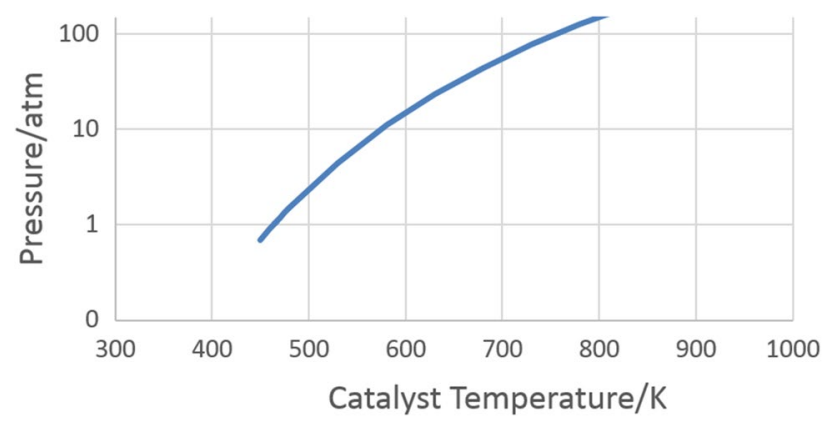

Fig. 4 The minimum pressure required in order to generate the reversible work needed to compensate for the increased catalyst temperature in the Haber-Bosch ammonia synthesis process. $p=\exp \left(W_{\text {deficit }} / \mathrm{R} T\right)$, where $W_{\text {deficit }}=16.40-45.9\left(1-T_{0} / T\right)$. In practice, a pressure of $200 \mathrm{~atm}$ is applied with $\sim T=770 \mathrm{~K}$
For this process, $T_{\text {Carnot }}$ has the unattainable value of $-577.5 \mathrm{~K}$.

Instead, an intermediate reversible process is proposed, making syngas $\left(\mathrm{CO}+2 \mathrm{H}_{2}\right)$, with the feasible $T_{\text {Carnot }}=808.8 \mathrm{~K}$.

$3 / 4 \mathrm{CH}_{4}(\mathrm{~g})+1 / 4 \mathrm{CO}_{2}(\mathrm{~g})+1 / 2 \mathrm{H}_{2} \mathrm{O}(\mathrm{l}) \rightarrow \mathrm{CO}(\mathrm{g})+2 \mathrm{H}_{2}(\mathrm{~g})$

$\Delta_{\mathrm{r}} G^{0}=118.0 \mathrm{~kJ} \mathrm{~mol}^{-1} ; \Delta_{\mathrm{r}} H^{0}=186.9 \mathrm{~kJ} \mathrm{~mol}^{-1}$;

$\Delta_{\mathrm{r}} G^{0} / \Delta_{\mathrm{r}} H^{0}=0.63$.

The syngas may then be converted reversibly to methanol at the feasible $\mathrm{T}_{\text {Carnot }}=385.6 \mathrm{~K}$.

$\mathrm{CO}(\mathrm{g})+2 \mathrm{H}_{2}(\mathrm{~g}) \rightarrow \mathrm{CH}_{3} \mathrm{OH}(\mathrm{l})$

$\Delta_{\mathrm{r}} G^{0}=-29.07 \mathrm{~kJ} \mathrm{~mol}^{-1} ; \Delta_{\mathrm{r}} H^{0}=-128.2 \mathrm{~kJ} \mathrm{~mol}^{-1}$;

$\Delta_{\mathrm{r}} G^{0} / \Delta_{\mathrm{r}} H^{0}=0.23$.

Adding the two separate reactions each at $\left(T_{0}, p_{0}\right)$ together corresponds to the single combined process. This can be treated as a vector addition on the GH diagram, where the overall single step is the resultant vector. This is illustrated in Fig. 5.

This vector addition is entirely analogous to the connection of two Process Boxes, as previously depicted in Fig. 1 and illustrated in Fig. 6

Overall, this system remains situated in an "inaccessible" region of the GH-diagram. This demonstrates that by coupling multiple reactions (as is well acknowledged in standard thermodynamic situations [15]) it is possible to move a process into regions that were previously out of bounds.

It should be noted that the procedure for reversible process design requires complex engineering with its own economic and environmental consequences in terms of equipment, heat transfer processes, and issues of control and so cannot lightly be contemplated. Research has been undertaken to achieve the design of reversible processes $[16,17]$ using a single two-dimensional $\mathrm{G}-\mathrm{H}$ diagram as previously stated and as illustrated in Fig. 5. This can be accomplished no matter how complex the overall process.

\section{Exergy analysis: an aside}

A reference base must be selected in order to have a measure of a quantity with an undefined zero such as altitude; for altitude, one refers to height above mean sea level (itself a somewhat ambiguous quantity). Once so defined, altitudes may be compared against this reference. In chemical thermodynamics, the choice of base for the enthalpy 
Fig. 5 Vector addition of two reversible reactions with the resultant producing a process that is located in a previously unachievable region. Note that the balance of masses permits the dashed vector to be moved from the origin and summed with the first reaction vector
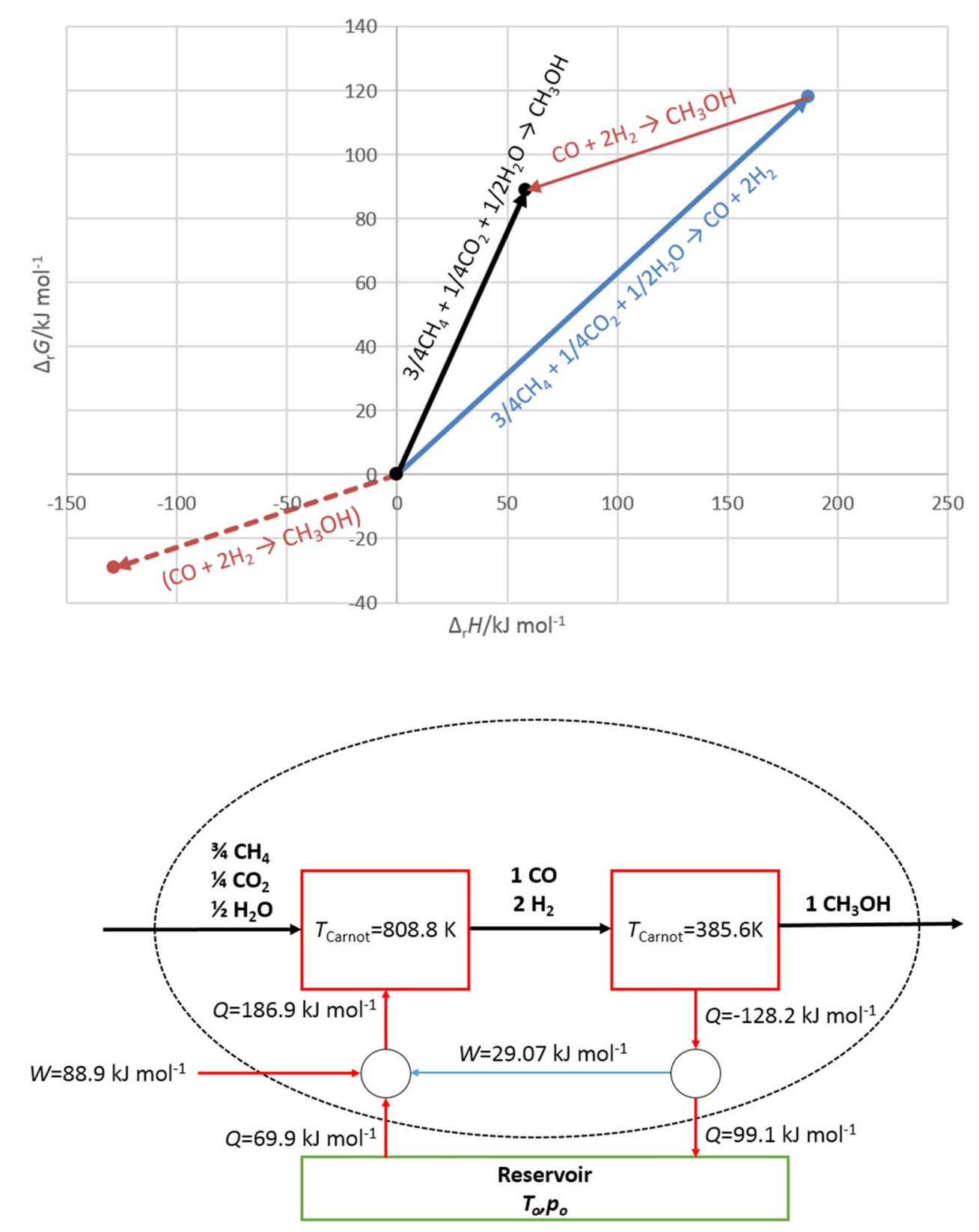

Fig. 6 A combination of two Process Boxes. The Carnot machine on the second (exothermic) process produces work, made reversible at $T_{\text {Carnot }}=385.6 \mathrm{~K}$, which is then used to power a Carnot machine connected to the first (endothermic) process. This Carnot machine upgrades energy from the reservoir to render the process reversible, by increasing the temperature of the heat transfer from $T_{0}$ up to $T_{\text {Carnot }}=808.8 \mathrm{~K}$. The nett heat supplied to the process is $88.9 \mathrm{~kJ} / \mathrm{mol}$ of materials is that each pure element in its reference phase (such as gas, liquid, or solid) under standard conditions of temperature $(298.15 \mathrm{~K})$ and pressure ( 1 bar) is assigned a value of zero. This definition involves multiple material references (that is, every element has its own zero), but is acceptable because the elements cannot be inter-converted under chemically relevant conditions.

With this reference established, we are able to compare materials and calculate the enthalpy changes in chemical processes. Furthermore, combining enthalpy changes with entropy changes, we are able to calculate Gibbs energy changes, which also presents us with values for work transfers, deficits or surpluses, as in the discussion above. The
Gibbs energy is a state function, independent of whether the overall process is performed reversibly or irreversibly.

When considering a chemical process for minimum work loss, the standard enthalpy reference selected may not always be the most useful since the pure element does not generally exist in its native form. Instead, an alternative choice for reference is the condition of the element as it exists in nature. For example, dry air consists of 20.9 vol\% of oxygen, so pure oxygen in contact with air requires the provision of energy in order to maintain the separation. Instead, using as reference the state of each element in nature, we obtain a new Gibbs energy, the exergy [6, 18-21]. Lists of exergy values for the elements in their reference state are available 


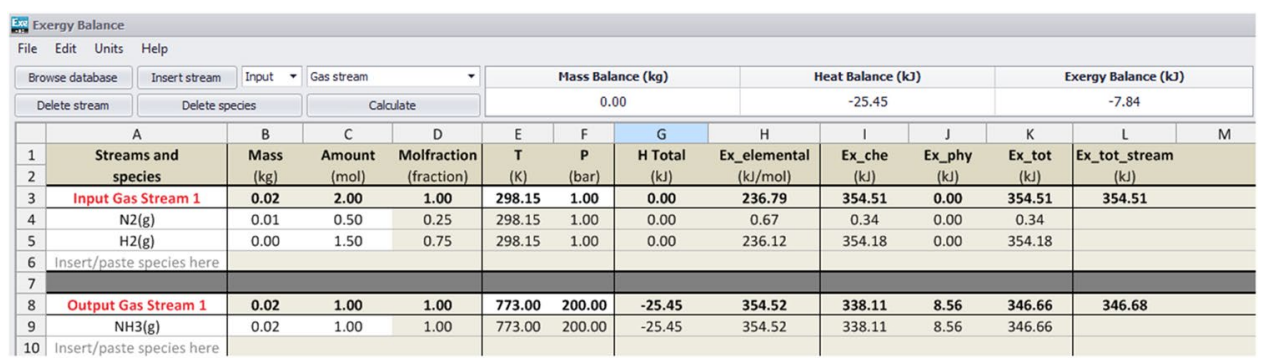

Fig. 7 The Exergy Balance Module of "HSC Chemistry" applied to the Haber-Bosch ammonia synthesis process, displayed as an Excel worksheet. Ex_elemental is the sum of the elemental exergies at the relevant temperature; $E x \_c h e$ is the chemical exergy, being the sum of Ex_elemental and of $\Delta G_{f}^{\circ}$ (elements); Ex_phy is the physical exergy, based on the ideal gas entropy: Ex_phy $=\left(H_{\mathrm{i}}-H_{\mathrm{i}}^{0}\right)-T\left(S_{\mathrm{i}}-S_{\mathrm{i}}^{0}\right)$.

$[22,23]$. This may be used in the chemical engineering field when it better represents the work changes in chemical processes which involve materials in their natural states, such as the use of air to provide oxygen, or where the materials are not under ambient conditions of temperature and pressure [24]. However, where purified materials are used under ambient conditions, there is no advantage in use of exergy rather than Gibbs energy. It should also be clear that exergy does not represent any change in equilibrium conditions. The software program "HSC Chemistry" contains an Exergy Balance Module [25], illustrated in Fig. 7.

The use of exergy in process optimization is not standard practice for either process design or process retrofit. Most research in this field focuses rather on other highly complex techniques, involving approaches such as Multiple Integer Non-Linear Programming (MINLP) [26], which effectively attempt to find the optimum in $n$ dimensions. While powerful, the adoption of these techniques outside of academia has been slow, perhaps partly due to the high level of complexity involved.

\section{Conclusions}

It is suggested that industrial processes can usefully be considered for preliminary optimisation of their overall thermodynamics by appropriate reversible heat and work transfers, where GH-diagrams (such as Figs. 3, 5) provide useful guides to the management of such optimisation.

The choice of catalyst and operating temperature is normally made before the process is designed in detail; however, these early stage decisions are probably the most important in determining the reversibility of the processes and hence the environmental impact of the process. It is thus very important that there are easy methods that require only readily available data, such as thermodynamic data, in order
Note that the exergy balance of $-7.84 \mathrm{~kJ} \mathrm{~mol}^{-1}$ is smaller than the energy balance value of $-11.80 \mathrm{~kJ} \mathrm{~mol}^{-1}$ noted in the paragraphs above since the exergy reference base for nitrogen gas is nitrogen in dry air rather than pure nitrogen gas. The values displayed are truncated to two significant figures

to optimise the process at the earliest possible stage in the process development. The optimised processes will certainly require modification to allow for the realities of available materials and equipment.

There is an opportunity for students to be introduced to these topics in the course of their normal study of thermodynamics. Chemists involved in developing industrial processes may simplify the task of chemical engineers by providing optimised procedures as starting points for industrial development.

Open Access This article is distributed under the terms of the Creative Commons Attribution 4.0 International License (http://creativeco mmons.org/licenses/by/4.0/), which permits unrestricted use, distribution, and reproduction in any medium, provided you give appropriate credit to the original author(s) and the source, provide a link to the Creative Commons license, and indicate if changes were made.

\section{References}

1. Denbigh KG (1956) The second-law efficiency of chemical processes. Chem Eng Sci 6(1):1-9. https://doi.org/10.1016/00092509(56)80005-5

2. Pal R (2017) Conceptual issues related to reversibility andreversible work produced in closed and open flowsystems. Educ Chem Eng 19:29-37

3. Bejan A (2002) Fundamentals of exergy analysis, entropy generation minimization, and the generation of flow architecture. Int $\mathrm{J}$ Energy Res 26:545-565

4. Bejan A (2016) Advanced engineering thermodynamics, 6th edn. Wiley, New York

5. Zhang L, Chen L, Xia S, Wang C, Sun F (2018) Entropy generation minimization for reverse water gas shift (RWGS) reactors. Entropy 20:415

6. Szargut J, Morris DR, Steward FR (1988) Exergy analysis of thermal, chemical, and metallurgical processes. Hemisphere Publishing Corporation, New York

7. Glasser L (2016) Correct use of helmholtz and gibbs function differences, $\Delta A$ and $\Delta G$ : the van't Hoff reaction box. J Chem Educ 93(5):978-980 
8. Atkins P (1998) Physical chemistry, 6th edn. Oxford University Press, Oxford

9. Patel B, Hildebrandt D, Glasser D, Hausberger B (2005) Thermodynamics analysis of processes. 1. Implications of work integration. Ind Eng Chem Res 44(10):3529-3537. https://doi. org/10.1021/ie048787f

10. Fox JA, Hildebrandt D, Glasser D, Patel B (2013) A graphical approach to process synthesis and its application to steam reforming. AlChE J 59(10):3714-3729

11. Fox JA, Hildebrandt D, Glasser D, Patel B, Hausberger B (2014) Process flow sheet synthesis: reaching targets for idealized coal gasification. AlChE J 60(9):3258-3266

12. Rivero R, De Oliveira Jr S, Le Goff P (1990) Température de Carnot $\Theta$, diagramme $\Theta / Q$, méthode du pincement. Application à l'analyse exergétique des procédés industriels. Entropie 26(157):13-20

13. Sempuga BC, Hildebrandt D, Patel B, Glasser D (2011) Work to chemical processes: the relationship between heat, temperature, pressure, and process complexity. Ind Eng Chem Res 50(14):8603-8619. https://doi.org/10.1021/ie2004785

14. Sempuga BC, Hausberger B, Patel B, Hildebrandt D, Glasser D (2010) Classification of chemical processes: a graphical approach to process synthesis to improve reactive process work efficiency. Ind Eng Chem Res 49(17):8227-8237. https://doi.org/10.1021/ ie $100288 \mathrm{~h}$

15. IUPAC Chemical Induction (Coupling). http://goldbook.iupac.org/ C01025.html. Accessed Jan 2016

16. Hildebrandt D, Glasser D, Patel B (2015) Making processes work. Comput Chem Eng 81:22-31

17. Fox JA, Hildebrandt D, Glasser D, Patel B (2017) Process flow sheet synthesis: systems-level design applied to synthetic crude production. AlChE J 63(12):5413-5424. https://doi.org/10.1002/ aic. 15818
18. Ayres RU, Ayres LW, Martinás K (1998) Exergy, waste accounting, and life-cycle analysis. Energy 23(5):355-363. https://doi. org/10.1016/S0360-5442(97)00076-5

19. Sankaranarayanan K, van der Kooi HJ, de Swaan Arons J (2010) Efficiency and sustainability in the energy and chemical industries: scientific principles and case studies, 2nd edn. CRC Press, Boca Raton, FL, USA

20. Szargut J (2005) Exergy method: technical and ecological applications. WIT Press, Southampton

21. Ayres RU, Talens Peiró L, Villalba Méndez G (2011) Exergy efficiency in industry: where do we stand? Environ Sci Technol 45(24):10634-10641. https://doi.org/10.1021/es202193u

22. Rivero R, Garfias M (2006) Standard chemical exergy of elements updated. Energy 31(15):3310-3326. https://doi.org/10.1016/j. energy.2006.03.020

23. Morris DR, Szargut J (1986) Standard chemical exergy of some elements and compounds on the planet earth. Energy 11(8):733755. https://doi.org/10.1016/0360-5442(86)90013-7

24. Kirova-Yordanova Z (2004) Exergy analysis of industrial ammonia synthesis. Energy 29(12):2373-2384. https://doi.org/10.1016/j. energy.2004.03.036

25. Outotec (2015) HSC Chemistry 8. Outotec research Oy. http:// www.outotec.com/en/Products-services/HSC-Chemistry/. Accessed Mar 2017

26. Vigerske S (2018) MINLPLib: a library of mixed-integer and continuous nonlinear programming instances. http://www.minlplib. org/. Accessed Apr 2018

Publisher's Note Springer Nature remains neutral with regard to jurisdictional claims in published maps and institutional affiliations. 